\title{
Influence of process parameters on the cathode current efficiency of $\mathrm{Zn} / \mathrm{SiO}_{2}$ electrodeposition
}

\author{
Tolumoye Johnnie Tuaweri, Emmanuel Munakurogha Adigio, Pressy Proctor Jombo \\ Department of Mechanical/Marine Engineering, Niger Delta University, Wilberforce Island, Amassoma, Bayelsa State, Nigeria
}

\section{Email address:}

Tuaweri@yahoo.com(T. J. Tuaweri),emadigio@yahoo.com(E. M. Adigio)

\section{To cite this article:}

Tolumoye Johnnie Tuaweri, Emmanuel Munakurogha Adigio, Pressy Proctor Jombo. Influence of Process Parameters on the Cathode Current Efficiency of $\mathrm{Zn} / \mathrm{SiO}_{2}$ Electrodeposition. International Journal of Mechanical Engineering and Applications.

Vol. 1, No. 5, 2013, pp. 93-99. doi: 10.11648/j.ijmea.20130105.11

\begin{abstract}
Cathode current efficiency (CCE) of $\mathrm{Zn} / \mathrm{SiO}_{2}$ composite electrodeposition bath was investigated. Influence of current density, particle loading, bath agitation, deposition time and bath additive were given particular attention. It was revealed that CCE and particle content in the deposit were inversely proportional to one another with increase in particle loading up to $80 \mathrm{~g} / \mathrm{l}$, beyond which both decreased. Influence of time on CCE for different particle loadings shows that CCE was significantly higher for baths with lower amount of particles than those with higher amount of particles. However, CCE shows an increasing trend with bath agitation for both $13 \mathrm{~g} / \mathrm{l}$ and $26 \mathrm{~g} / \mathrm{l}$ particle loading with that of $26 \mathrm{~g} / \mathrm{l}$ being higher for all amplitudes investigated. Also, addition of $\mathrm{NaNO}_{3}$ additive into the bath was found to improve the $\mathrm{CCE}$ of the bath. Influence of current density was investigated for a bath with $104 \mathrm{~g} / \mathrm{l}$ of $\mathrm{SiO}_{2}$. The results show a sharp decrease in CCE from current density of $15 \mathrm{~A} / \mathrm{dm}^{2}$ and were constant for higher current densities up to $30 \mathrm{~A} / \mathrm{dm}^{2}$. Morphological changes accompanied changes in CCE.
\end{abstract}

Keywords: Zinc, Composite electrodeposition, Morphology, Cathode current efficiency, $\mathrm{SiO}_{2}$

\section{Introduction}

Research on the production of composite coatings via electrolytic routes has been widely investigated in recent years [1-8]. When inert particles such as oxides, are incorporated into a metal matrix, its functional properties are changed depending on the type of particles incorporated $[1,2]$. Not only are the properties of the coatings changed with the type of particles, but also their rate of codeposition as reported [6] in a recent study where Silicon carbide ( $\mathrm{SiC}$ ) incorporation was found to be better than that of silica $\left(\mathrm{SiO}_{2}\right)$. Some of the properties obtained as a result of such codeposition include wear resistance, high temperature corrosion resistance, oxidation resistance and self lubrication. Most research effort made in composite electrodeposition has been directed towards the determination of optimum values of current density, temperature, bath particle loading, and bath composition [3] for maximum particle incorporation, often leaving out their influence on CCE. Amongst these variables, influence of applied current density on the CCE has been given particular attention $[3,4,5]$ with few isolated cases on its influence by other parameters. Cathode current efficiency is an important electrochemical indicator of an electrodeposition process especially in terms of energy consumption. It is defined as the ratio between actual amounts of metal deposition to that which would have resulted if all the current had been used for deposition [10]. It depends not only on the applied current, but also on the other coating conditions [10].

The efficiency of the electrodeposition process, microstructure, morphology, nature of electrodeposits and the properties exhibited are largely a function of how this parameter is controlled by other variables. Afshar et al [3] investigated the $\mathrm{CCE}$ of bronze bath at temperatures of $40^{\circ} \mathrm{C}$ and $70^{\circ} \mathrm{C}$ and reported that $\mathrm{CCE}$ declined with increase in current density with a higher efficiency at $40^{\circ} \mathrm{C}$. This behavior was attributed to polarization at the surface of the cathode. Furthermore, with the introduction of graphite into the bath, the CCE increased with increasing graphite loading and was attributed to the conductivity of graphite. Variations in $\mathrm{CCE}$ of a bronze bath with current density at different temperatures have also been reported [4]. According to these authors, cathode current efficiency 
decreased with increase in current density and was also attributed to cathode polarization and mass transfer limitations [4]. In a similar study on $\mathrm{Ni}-\mathrm{SiC}$ bath, it was reported [5] that the cathode current efficiency decreased with increase in current density for temperatures of $30^{\circ} \mathrm{C}$ and $60^{\circ} \mathrm{C}$ with the efficiency higher at $30^{\circ} \mathrm{C}$. However, it increased with increasing $\mathrm{SiC}$ bath loading.

Furthermore, it was reported [11] that maximum current efficiency was responsible for the co-deposition of a maximum amount of $\mathrm{Al}_{2} \mathrm{O}_{3}$ particles $(4.3 \mathrm{wt} \%$ ) in the coatings. Despite several research works on the effect of operating conditions on the electrodeposition process and properties of nano-composites coatings, few have examined the influence of these conditions on the current efficiency of a $\mathrm{Zn} / \mathrm{SiO}_{2}$ bath. This work therefore seeks to report findings on the influence of current density, particle loading, deposition time, bath additive and bath agitation on the cathode current efficiency of a $\mathrm{Zn} / \mathrm{SiO}_{2}$ electrodeposition bath.

\section{Experimental Methods and Materials}

Electrolytes for the production of $\mathrm{Zn} / \mathrm{SiO}_{2}$ electrodeposits were prepared from an acid sulphate bath with standard laboratory reagents containing $250 \mathrm{~g} / \mathrm{l}$ $\mathrm{ZnSO}_{4} \cdot 7 \mathrm{H}_{2} \mathrm{O}, 80 \mathrm{~g} / 1 \mathrm{Na}_{2} \mathrm{SO}_{4}, \mathrm{pH}$ 2.0-2.5. Silica particles with an average size of $20 \mathrm{~nm}$ in a $40 \%$ aqueous colloidal suspension with density of $1.3 \mathrm{~g} / \mathrm{cm}^{2}$ were utilised as received from Alfa Aesar with no further pre-treatment or surface modification. Influence of $\mathrm{NaNO}_{3}$ as an inorganic additive was also investigated. A solution of it was prepared with distilled water and the required concentration was added directly into the individual baths.

The electrolytic codeposition was carried out using a simple electrolytic cell and associated control equipment, which was made up of a power supply unit, two electrode supports, mild steel cathode, and a zinc anode. The range of current densities was $1-40 \mathrm{~A} / \mathrm{dm}^{2}$. All the electrodeposition experiments were carried out galvanostatically using DC currents. The anode material was 99\% zinc foil. Bath agitation was effected using magnetic stirring and vibratory agitation both described in detail elsewhere in a previous work [2].

Weight gain method was used to determine deposit thickness and cathode current efficiency using Faraday's Law. Mean values of deposit thickness were deduced and percentage cathode current efficiencies determined. Surface morphology studies were carried out using, a Leo model 1530 field emission gun scanning electron microscope (FEGSEM). The same equipment was used to analyse the deposit composition each being fitted with an X-ray energy dispersive analysis system (EDX) and the weight percentage of silicon obtained was converted to the weight percentage of silica.

\section{Results and Discussions}

\subsection{Influence of Current Density}

Results from the investigation of the influence of current density on cathode current efficiency using baths with 26 $\mathrm{g} / \mathrm{l}$ and $104 \mathrm{~g} / \mathrm{l}$ of $20 \mathrm{~nm}$ particles are demonstrated in Table 1 and Fig. 1 respectively.

Table 1. Relationship between current density, time and cathode current efficiency with a $\mathrm{SiO}_{2}(20 \mathrm{~nm})$ concentration in bath of $26 \mathrm{~g} / \mathrm{l}$

\begin{tabular}{|c|c|c|}
\hline \multirow{2}{*}{$\begin{array}{l}\text { Deposition time, } \\
\text { Seconds }\end{array}$} & \multicolumn{2}{|c|}{ Cathode current efficiency, \% } \\
\hline & $30 \mathrm{~A} / \mathbf{d m}^{2}$ & $40 \mathrm{~A} / \mathrm{dm}^{2}$ \\
\hline 60 & 70 & 69 \\
\hline 75 & 84 & 82 \\
\hline 90 & 76 & 60 \\
\hline
\end{tabular}

Although, there is no significant difference, Table 1 shows that the majority of the current efficiency values at $30 \mathrm{~A} / \mathrm{dm}^{2}$ were higher than the corresponding values at 40 $\mathrm{A} / \mathrm{dm}^{2}$, which appears to complement the observations in Fig. 1. The general trend indicates that current efficiencies are higher at lower current densities for the experimental conditions investigated. Such behavior could be attributed to polarization at the surface of the cathode [12]. Ghorbani et al [12] while studying a graphite-brass composite coating system also reported that cathode current efficiency of the system declined with the increase in current density.

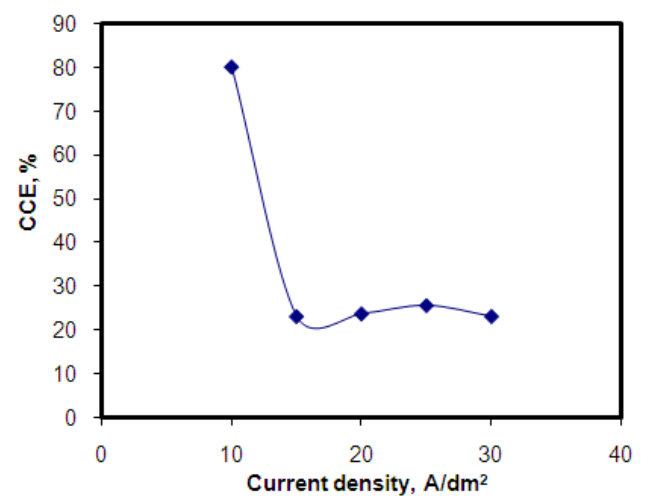

Fig 1. Influence of current density on $\mathrm{CCE}$ of a $\mathrm{Zn} / \mathrm{SiO}_{2}$ bath containing $104 \mathrm{~g} / \mathrm{l} \mathrm{SiO}$, and amplitude of vibration $0.55 \mathrm{~mm}$

Furthermore, Fig. 1 shows that there was no significant change in the cathode current efficiency of the bath within a wide range of current densities. This behavior is probably due to the high particle concentration of the bath. Current density of $10 \mathrm{~A} / \mathrm{dm}^{2}$ gave significantly high current efficiency of about $80 \%$. However, at a current density range from $15 \mathrm{~A} / \mathrm{dm}^{2}$ to $30 \mathrm{~A} / \mathrm{dm}^{2}$, change in cathode current efficiency was negligible. Apart from polarisation effects, the sudden reduction in current efficiency at a current density of about $15 \mathrm{~A} / \mathrm{dm}^{2}$ is an indication that agglomeration of silica particles probably occurred. This was practically evident, as the viscosity of the solution was observed to increase. Agglomerated particles have a 
tendency to adsorb onto surfaces and therefore may have adsorbed onto the surface of the cathode thereby blocking off the surface of the cathode from reducible species and consequently causing the decrease in cathode current efficiency.

\subsection{Influence of Particle Concentration in the Bath}

The relationship between particle loading, weight percentage of particles in deposit and cathode current efficiency is shown in Fig 2. It shows that cathode current efficiency decreases as the particle concentration increases. The trend appears to take a linear fashion for all bath concentrations investigated. This decrease in cathode current efficiency is probably due to an increase in solution resistance.

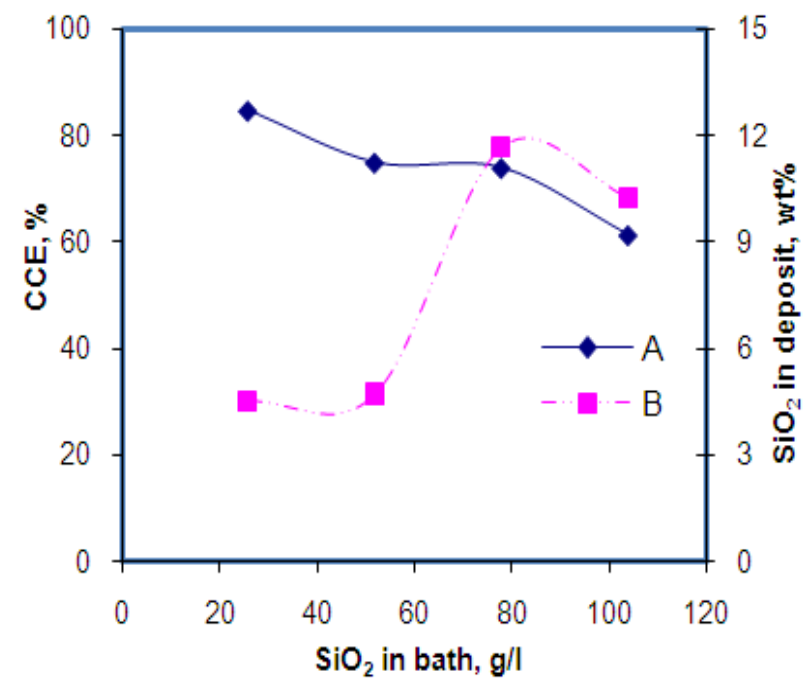

Fig 2. Effect of particle loading on (A) CCE and (B) rate of particle incorporation in the deposit. $\mathrm{SiO}_{2} 20 \mathrm{~nm}, 500 \mathrm{rpm}$, Time 60 seconds, pH 2 and $30 \mathrm{~A} / \mathrm{dm}^{2}$

Since silica particles in question are non-conducting components of the composite bath, it is not surprising that increasing their concentration in the bath could lead to a corresponding decrease in solution conductivity and hence cathode current efficiency. On the contrary, rate of particle incorporation appears to increase with increase in particle loading up to a maximum of $80 \mathrm{~g} / \mathrm{l}$. Beyond this particle bath loading, a decreasing trend in particle incorporation is observed. This is an indication that up to the maximum bath loading of $80 \mathrm{~g} / \mathrm{l}$, cathode current efficiency and particle incorporation were inversely proportional. However, beyond this bath concentration of particles, both particle incorporation and cathode current efficiency begins to decrease. This decrease may not only be attributed to poor solution conductivity but also to possible agglomeration. Similar observations have previously been reported [13]. They reported that solution resistance in an electro-galvanising bath in the presence of particles could become unnecessarily high, resulting in a poorer current efficiency and increased consumption of electric power for electrogalvanising.

\subsection{Influence of Deposition Time}

Figs. 3 and 4 show the influence of deposition time on the CCE of the composite baths. There are two distinct trends exhibited. In Fig. 3, the CCE increases with increase in deposition time up to a maximum at 180 seconds and decreases with further increase in time while in Fig. 4 CCE shows a decreasing trend with increase in time. Figure 3 is indicative of a trend where, when current is applied, there occurs reduction of zinc ions.

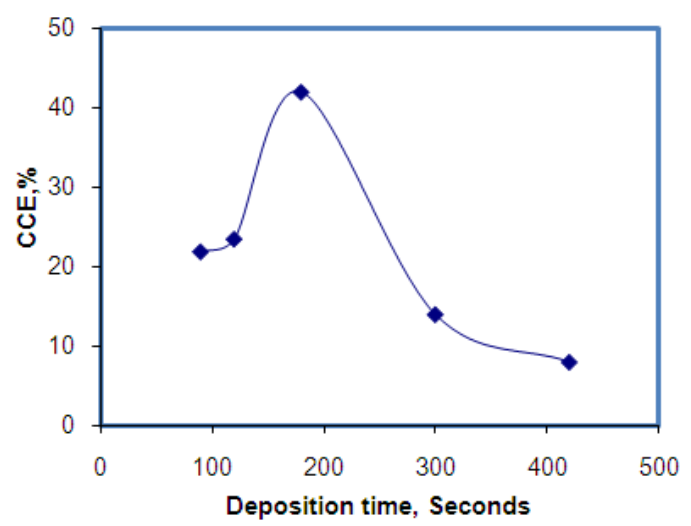

Fig 3. Dependence of cathode current efficiency on deposition time. Current density $30 \mathrm{~A} / \mathrm{dm}^{2}$, particle loading $104 \mathrm{~g} / \mathrm{l}$, bath agitation $500 \mathrm{rpm}$, pH 2.0.

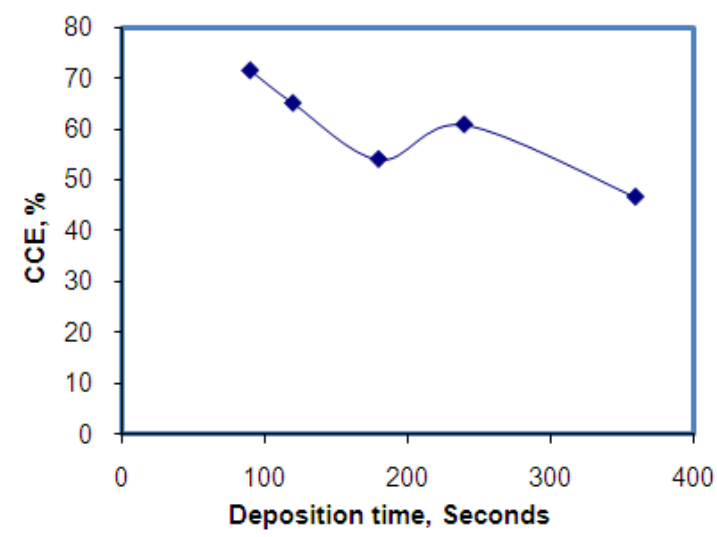

Fig 4. Dependence of cathode current efficiency on deposition time. Current density $30 \mathrm{~A} / \mathrm{dm}^{2}$, particle loading $26 \mathrm{~g} / \mathrm{l}$, bath agitation $500 \mathrm{rpm}$, pH 2.0

However, as the deposit build up with time, $\mathrm{pH}$ at the vicinity of the cathode increases and catalyses the process agglomeration and subsequent codeposition of these agglomerated particles. 180 seconds appear to be the optimum deposition time for maximum current efficiency of the said bath. The sudden decrease in CCE with further increase in deposition time beyond 180 seconds is probably due to codeposition of the agglomerated particles causing a "blocking" effect $[14,15]$ as a layer on the cathode thereby reducing the overall active surface area for further metal deposition. This layer could have an inhibitive effect to random deposition as deposition occurs only when metal ions arriving at the cathode can pass through this layer [16]. There appears to be some consistency of the 
aforementioned with Fig. 5. Fig. 5 shows a cross sectional view of a $\mathrm{Zn} / \mathrm{SiO}_{2}$ composite electrodeposit. As evident, there are three distinct regions on this coating; a relatively compact underlayer of zinc, a discontinuous middle layer of dendritic 'trees' of zinc with vertical silica layers in between and a topcoat of predominantly dense silica. Similar coatings have previously been reported $[17,18]$.

The discontinuous nature of the middle layer with pockets of porosity in the form of black holes may have been as result of hydrogen evolution. The formation and subsequent build up of these distinctive layers appear to be a function of time and $\mathrm{pH}$ of the bath. Apparently, at the beginning of coating formation, the current efficiency may have been good hence the relatively compact underlayer of zinc deposit. However, as the deposit builds up with time, $\mathrm{pH}$ of the bath increases; catalyzing the process of agglomeration and subsequent codeposition of these agglomerates. The codeposited agglomerates reduce the cathode surface area and induce localized zinc deposition leading to the formation of dendritic zinc "trees" apparently struggling to build up through a dense mass of silica topcoat. At the first stage of deposition, when the reaction area of zinc deposition is small, the release of hydrogen bubbles will cause parasites or dendrites [19]. Moreover, high deposition and growth rate of metal nuclei at some sites are prone to promote dendritic growth [20].

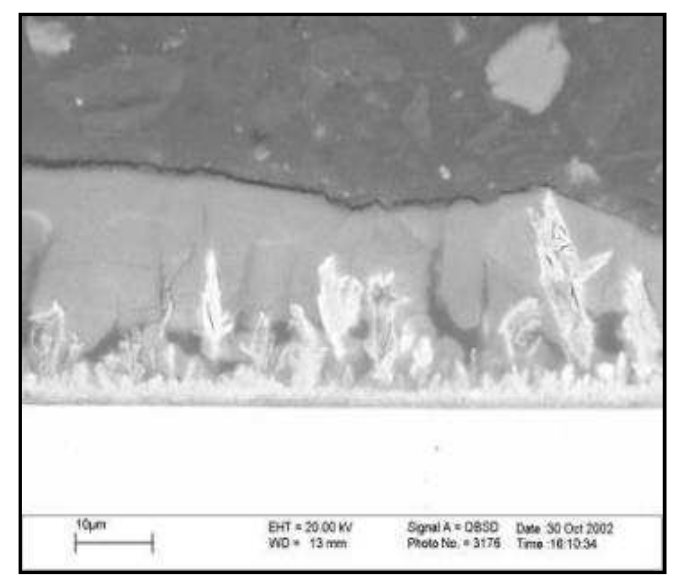

Fig 5. SEM micrograph of a cross-sectional view of $\mathrm{Zn} / \mathrm{SiO}_{2}$ electrodeposit. Current density $30 \mathrm{~A} / \mathrm{dm}^{2}$, particle loading $104 \mathrm{~g} / \mathrm{l}$, bath agitation $500 \mathrm{rpm}, \mathrm{pH} 2.0$

Although this could not be confirmed at this stage and require further investigations, CCE may have decreased from bottom to top of Figure 5 as it is obvious from the micrograph that zinc deposition appears better at the bottom, dendritic in the middle and minimal at the top. It appears that the possible variation in CCE as the deposit builds up is dependent on the amount of particle bath loading.

By comparing Figs 3 to 5 , it can be deduced that the region between 90-180 seconds in Fig. 3 represents the region of good $\mathrm{CCE}$ for the deposition of the zinc underlayer while the region between 180-400 seconds represents the gradual decrease in CCE with the initiation and subsequent formation of the dendritic middle layer through to the top of the coating in Fig. 5. Also, Fig 3 and 4 shows the influence of deposition time on the CCE of the baths with $104 \mathrm{~g} / \mathrm{l}$ and $26 \mathrm{~g} / \mathrm{l}$ respectively. CCE of the bath with $26 \mathrm{~g} / 1$ was significantly higher than that with $104 \mathrm{~g} / \mathrm{l}$ for all the durations. As earlier mentioned, solution resistances could be higher for baths with excessively higher particle loading. Moreover, CCE to a large extent depends on the conductivity of the solution and could therefore decrease with increase in inert particles bath loading beyond an optimum concentration which may be specific to individual bath conditions. When adsorbed particles exceed a certain amount, they may inhibit metal deposition as this could create a requirement for additional overpotential for deposition to occur [8].

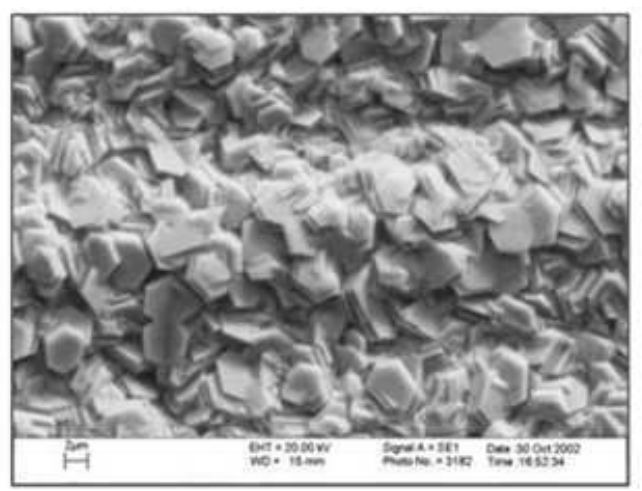

a

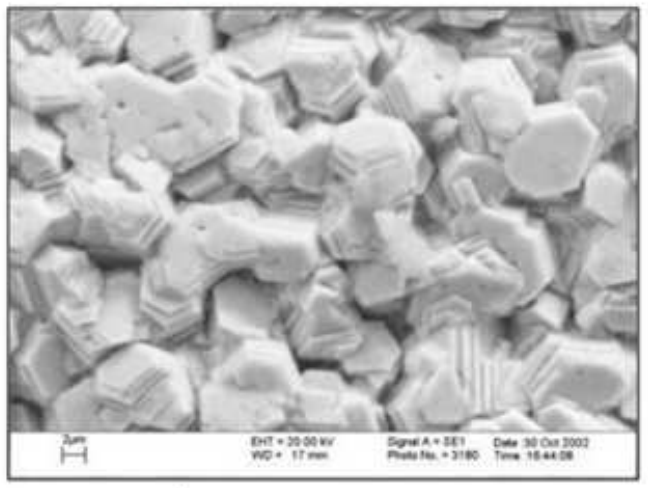

b

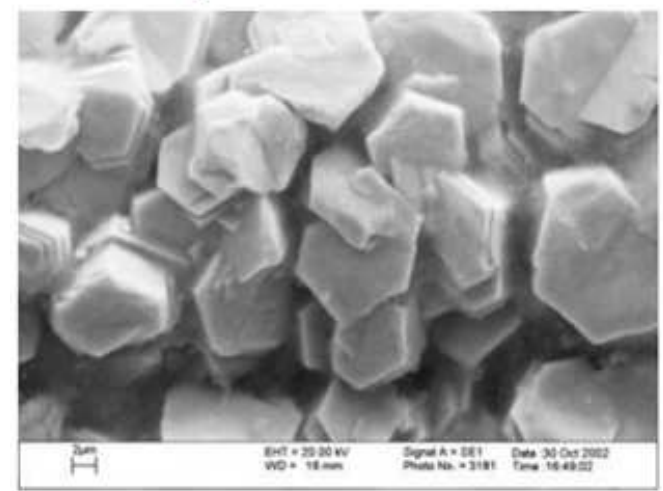

c

Fig 6. SEM micrographs showing the surface morphologies of $\mathrm{Zn} / \mathrm{SiO}_{2}$ electrodeposits produced at a current density of $30 \mathrm{~A} / \mathrm{dm}^{2}$ (A) CCE-71.4\% (B) $C C E-60.8 \%$ (C) $C C E-46.6 \%$ 
Fig. 6(a,b,c) shows morphologies of coatings produced at different current efficiencies. A unique trend is evident here. Figure $6 \mathrm{a}$ produced at a CCE of $71.4 \%$ exhibits relatively uniform lateral deposition of hexagonal zinc crystals evidently giving good coverage to the underlying steel substrate. As the CCE decreased to $60.8 \%$ (fig. 6b) the hexagonal crystals tend to increase in size and forms "Islands" of vertically stacked zinc crystals. With further decrease in CCE to $46.6 \%$ (fig 6c), the sizes of each Island and gaps between them increases, leaving sufficient room for the codeposition of vertical layers of agglomerated silica. The formation of these gaps may not be unconnected with pathways of hydrogen evolution associated with $\mathrm{pH}$ increase with deposition time which becomes filled with silica codeposits.

\subsection{Influence of Bath Agitation}

Figs 7 and 8 show the effect of bath agitation on the CCE of the baths, with different particle loading and $\mathrm{NaNO}_{3}$ concentrations respectively. Two baths with different amounts of $\mathrm{SiO}_{2}$ particles were investigated in Fig. 7. Cathode current efficiency tends to increase slightly with increase in bath agitation for both baths. This increase may be attributed to enhanced mass transfer occasioned by agitation. Evidently, the bath with $26 \mathrm{~g} / \mathrm{l}$ of $\mathrm{SiO}_{2}$ showed a higher CCE than that with $13 \mathrm{~g} / \mathrm{l}$. This may be attributed to the frequency of particles with adsorbed zinc ions reaching the surface of the cathode [2].

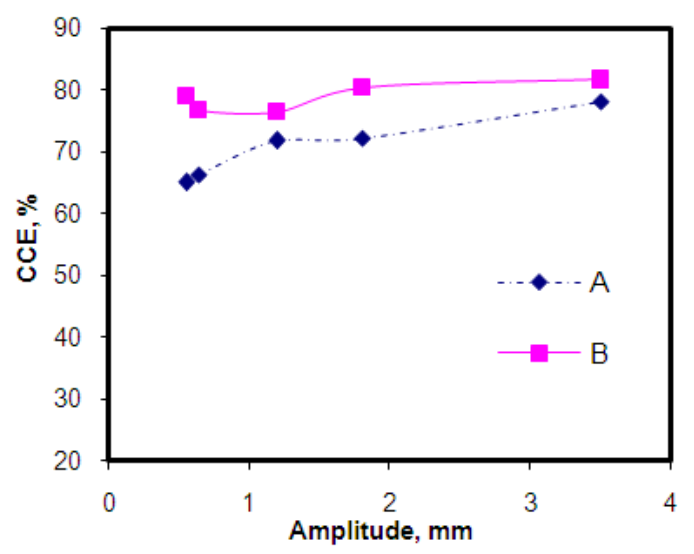

Fig 7. Dependence of cathode current efficiency on bath agitation for particle bath loading of (A) $13 \mathrm{~g} / \mathrm{l}$ and (B) $26 \mathrm{~g} / \mathrm{l}$. Current density 30 $A / \mathrm{dm}^{2}$, particle size $20 \mathrm{~nm}$

The importance of bath agitation and mass transport playing significant role in particle incorporation with their effectiveness being dependent on particle bath loading has been reported in our previous work [2]. Gugliemi [21] two step adsorption theory, reported about solid particles surrounded by a cloud of ions. In the first step, when the particles approach the cathode they become weakly adsorbed at the cathode by Van der Waals forces. In the second step, particles adsorb strongly on the cathode surface by Coulombic forces and consequently become incorporated into the growing metal matrix [11]. This model does not consider mass transfer. However, a generally accepted mechanism suggested by Kurozaki [22] includes the transport of solid particles from the solution to the cathode surface by agitation. As more particles reach the surface of the cathode with adsorbed ions, the more likely a higher current efficiency.

\subsection{Influence of Bath Additive}

Fig. 8 shows the influence of sodium nitrate $\left(\mathrm{NaNO}_{3}\right)$ on the CCE of the composite baths. Evidently, the presence of $\mathrm{NaNO}_{3}$ improved the $\mathrm{CCE}$ of the bath. CCE of the bath with $\mathrm{NaNO}_{3}$ was higher than that without $\mathrm{NaNO}_{3}$ for all amplitudes of vibration. Increase in CCE for zinc electrodeposition from acid baths in the presence of additives has been reported [23].

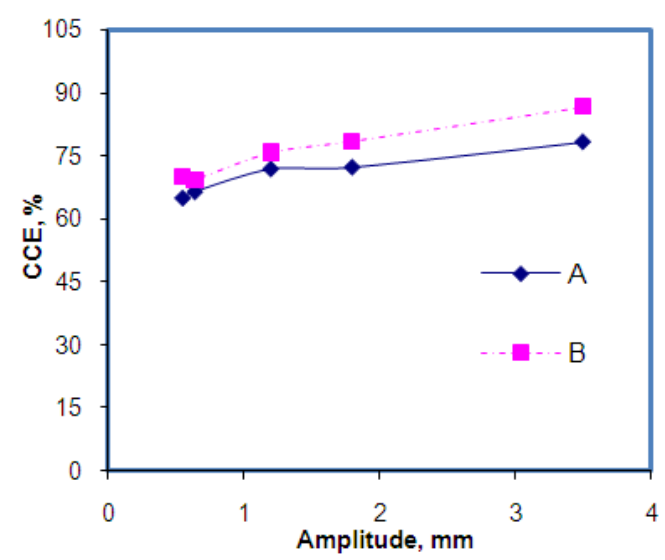

Fig 8. Dependence of cathode current efficiency on bath agitation (A) 0 ppm $\mathrm{NaNO}_{3}$ and (B) 1000 ppm $\mathrm{NaNO}_{3}$. Current density $30 \mathrm{~A} / \mathrm{dm}^{2}$, particle size $20 \mathrm{~nm}$.

The choice of $\mathrm{NaNO}_{3}$ in the present work was dictated by the fact that nitrates have been reported [24, 25] to inhibit corrosion. The reason for the improvement in CCE with the addition of $\mathrm{NaNO}_{3}$ is not very clear but could be attributed to rise in ionic content of the bath. Also, sodium nitrate may have acted as a catalyst and probably changed the kinetics of competitive reaction between zinc deposition and hydrogen evolution with preference for the first as assumed by Mouanga et al [23] for zinc electrodeposition in the presence of Coumarin and Ciszewski et al [26] in the case of saccharin and quaternary ammonium chlorides on the electrodeposition of nickel from a Watts-type electrolyte.

\subsection{Current Efficiency and Deposit Morphology}

Figs. 6 and 9 show the relationship between current efficiency and deposit morphology. The cathode current efficiency of each of these deposits differed from one another. From Fig. 9(a,b), SEM analysis revealed that the bright portions were zinc and the darker regions gave mainly silicon peaks. It is evident that the regions showing zinc patches are more for that with a higher current efficiency (see fig. 9b). This appears to be an issue of available sites for the nucleation and hence reduction of zinc ions. 


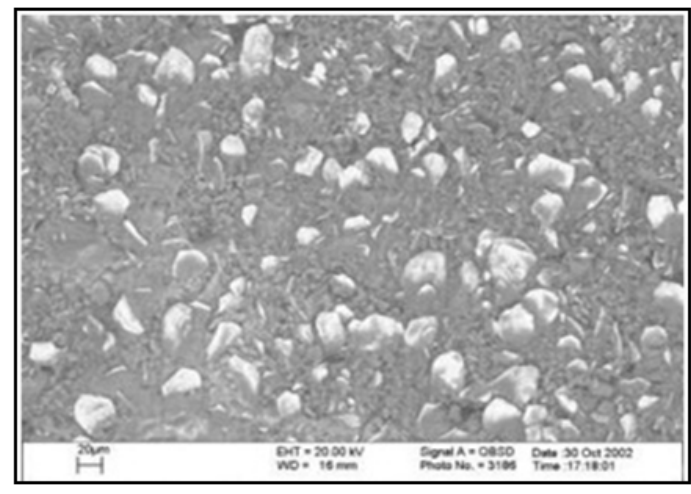

a

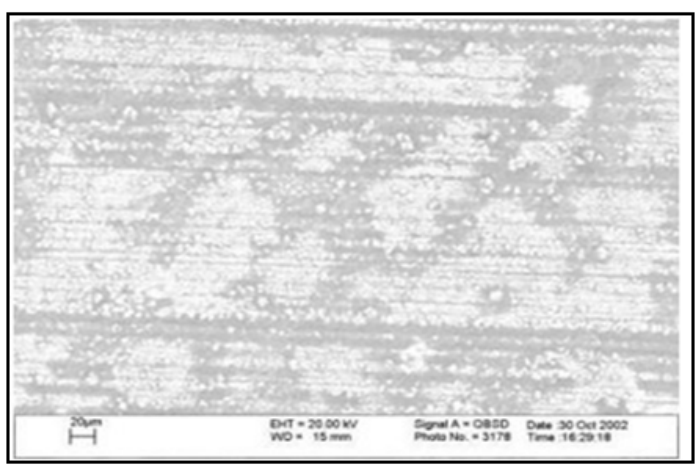

b

Fig 9. SEM micrographs showing the surface morphologies of $\mathrm{Zn} / \mathrm{SiO}_{2}$ electrodeposits produced at cathode current efficiencies of (a) $8 \%$ and (b) $23.5 \%$.

The current efficiency was highest for the morphology (9b) with more 'islands' of zinc as white patches unevenly distributed in the dense mass of codeposited silica seen as the dark portions. Such islands of electrodeposited zinc on the surface of the morphology may have provided more active sites for the reduction of incoming zinc ions. On the other hand, it was obvious that the morphology (9a) with fewer of these white zinc patches exhibited extremely low cathode current efficiency of $8 \%$. Because the dense mass of deposited silica is largely inert, rather than providing sites for the deposition of zinc, it covers up large areas for possible metal ion reduction, which may have contributed to the observed decrease in cathode current efficiency. Similar observations on the 'blocking' effect of particles thereby reducing the electrode surface area have been reported [14]. Particles that are being embedded in the growing metal layer cause an apparent decrease in the electrode surface area, probably due to the blocking effect on the surface by partly engulfed particles[14]. Also, particles being embedded in the surface do not only increase the surface inhomogeneity but also make the microscopic current distribution over the surface more uneven [14]. Electrode blocking by particles could result in additional $\mathrm{pH}$ increase within the vicinity of the cathode which may have promoted hydroxide formation [15]. Such hydroxides together with codeposited agglomerates could create a barrier effect and thus hinder zinc deposition and reduce the cathode current efficiency of the bath.

\section{Conclusions}

Cathode current efficiency of $\mathrm{Zn} / \mathrm{SiO}_{2}$ bath appears to have varied response to different deposition parameters. It was found to depend largely on particle bath loading.

Plating time was also found to have significant influence on the CCE of $\mathrm{Zn} / \mathrm{SiO}_{2}$ bath. For baths with high amount of silica particles, CCE increases at the begining of the deposition to a maximum and then decreased. However, for low and moderate bath concentration of particles, CCE only decreases with deposition time.

For the deposition conditions investigated, agitation tends to enhance the $\mathrm{CCE}$ of the bath. Addition of sodium nitrate $\left(\mathrm{NaNO}_{3}\right)$ to the bath also enhanced its $\mathrm{CCE}$. It was also deduced that morphological changes accompanied changes in CCE of the bath.

\section{Acknowledgements}

The authors wish to thank the sponsors of this project, Bayelsa State Government of Nigeria and the Niger Delta University, Wilberforce Island. Thanks also to Dr. G.D Wilcox for his invaluable guidance throughout this project.

\section{References}

[1] X. Bin-shi, W. Hai-dou, D. Shi-yun, J. Bin and T. Wei-yi, Electrodepositing Nickel Silica Nano-Composites Coatings, Electrochemistry Communications 7, pp 572-575 (2005)

[2] T. J. Tuaweri and G. D. Wilcox, Influence of $\mathrm{SiO}_{\text {, Particles }}$ on Zinc-nickel Electrodeposition, Transactions of the Institute of Metal Finishing, 85, pp 245-253 (2007)

[3] A. Afshar, M. Ghorbani and M. Mazaheri, Electrodeposition of Graphite-Bronze Coatings and Study Of Electroplating Characteristics, Surface \& Coating Technology, 187, pp 293-299 (2004)

[4] R. Balaji, M. Pushpavanam, K. Yogesh and K, Kumar, Subramanian, Electrodeposition of bronze-PTFE composite coatings and study of their tribological characteristics, Surface \& Coating Technology, 201, pp 3205-3211 (2006)

[5] M. R Vaezi, S.K Sadrnezhaad and L. Nikzad, Electrodeposition of Ni-Sic Nano-Composite Coatings and Evaluation of Wear And Corrosion Resistance and Electroplating Characteristics, Colloids and Surfaces A: Physicochem. Eng. Aspects 315, pp 176-182, (2008)

[6] G. Yu, X. Huang, C. Zou, L. Chen, B. Hu, L. Ye, Preparation of graphite@ $\mathrm{Cu}$ powders from ultrasonic powdering technique, Advance Powder Technology, 23, pp16-21 (2012)

[7] R. Manu, S. Priya, Implication of electrodeposition parameters on the architecture behaviour of MWCNTincorporated metal matrix. Applied Surface Science 284, pp 270-277 (2013). 
[8] Y. Yang, Y. F. Cheng, Fabrication of Ni-Co-SiC composite coatings by pulse electrodeposition- Effects of duty cycle and pulse frequency, Surface and Coating Technology, 216, 282-288 (2013)

[9] R. P. Socha, P. Nowak, K. Laajalehto, and J. Vayrynen, Particle-Electrode Surface Interaction During Nickel Electrodeposition from Suspensions Containing $\mathrm{SiC}$ and $\mathrm{SiO}_{2}$ Particles", Colloids and Surfaces A, 235, pp 45-55 (2004)

[10] F.A. Lowenheim, Modern Electroplating, $3^{\text {rd }}$ ed. John Wiley, USA, 7 (1974)

[11] R.K. Saha and T.I. Khan, Effect of applied current on the electrodeposited $\mathrm{Ni}-\mathrm{Al}_{2} \mathrm{O}_{3}$ composite coatings, Surface \& Coating Technology, 205, pp 890-895 (2010)

[12] M. Ghorbani, M. Mazaheri, K. Khangoli and Y. Kharazi, Electrodeposition of graphite-brass composite coatings and characterization of the tribological properties, Surface \& Coating Technology, 148, pp 71 (2001)

[13] M Abe, Y Shiohara, T Adaniya and H Naemura, Composite Zinc-Silica Electro-Galvanized Steel Sheet Excellent in Corrosion Resistance - US Patent 4,839,241, (1989)

[14] P. Nowak, R.P. Socha, M. Kaisheva, J. Fransaer, J.P. Celis and Z. Stoinov, Electrochemical Investigation of The Codeposition of $\mathrm{SiC}$ And $\mathrm{SiO}$, Particles With Nickel, J. Appl. Electrochem., 30, Issue 4, pp 429-437 (2000)

[15] D. Aslandis, J. Fransaer, and J.P Celis, J. Electrochem. Soc., 144 (7), pp 2352 (1997)

[16] H.B Muralidhara and Y. A. Naik, Electrochemical Deposition Of Nanocrystalline Zinc On Steel Substrate From Acid Zincate Bath, Surface \& Coating Technology, 202 pp 3403-3412 (2008)
[17] T. J. Tuaweri and G. D. Wilcox, Behaviour of $\mathrm{Zn}-\mathrm{SiO}_{2}$ Electrodeposition in the Presence of N.Ndimethyldodecylamine, Surface \& Coating Technology, 200, pp5921-5930 (2006)

[18] A. Takahashi, Y. Miyoshi and T. Hada, Surf. Technol., 44, pp 977 (1993)

[19] B. Sharifi, M. Mojtahedi, M. Goodarzi and J.V. Khaki, Effect of Alkaline Electrolysis Conditions on Current Efficiency and Morphology Of Zinc Powder, Hydrometallurgy 99, pp 72 (2009)

[20] W. Huang, M. Wang, H. Wang, N. Ma and X. Li, The Electrodeposition of Aluminium on $\mathrm{Tib}_{2} / \mathrm{A} 356$ Composite from Ionic Liquid as Protective Coating, Surface \& Coatings Technology, 213, pp 264-270 (2012)

[21] N. Guglielmi, Kinetics of the Deposition of Inert Particles from Electrolytic Baths, J. Electrochem. Soc. 119, pp 1009 (1972)

[22] K. Kurozaki, J. Jpn. Inst. Met. 10 (1979)

[23] M. Mouanga, L. Ricq, G. Douglade, J. Douglade and P. Bercot, Influence of coumarin on zinc electrodeposition, Surface \& Coating Technology 201, pp 762-767 (2006)

[24] M. Abe, S. Yukimitsu, A. Takeshi and N. Hiroshi, United States Patent, 4,839,241 June, (1989)

[25] T. J. Tuaweri, Zinc and zinc alloy composite coatings for corrosion protection and wear resistance, P.hD Thesis Loughborough Univ. pp 135 (2006)

[26] A. Ciszewski, Posluszny, G. Milczarek and M. Baraniak, Effects of saccharin and quaternary ammonium chlorides on the electrodeposition of nickel from a Watts-type electrolyte, Surface \& Coatings Technology, 183, pp. 127-133 (2004) 